\title{
Influence of secretory leukocyte protease inhibitor (SLPI) based peptides on elastase activity and their incorporation in hyaluronic acid hydrogels for chronic wound therapy
}

\author{
Sandra Cerqueira Barros ${ }^{1}$, José Alberto Martins ${ }^{1}$, João Carlos Marcos ${ }^{1}$, Artur \\ Cavaco-Paulo ${ }^{2 *}$ \\ 1-Center of Chemistry, University of Minho, Campus de Gualtar, 4710-057 Braga, Portugal \\ 2-Textil Engineering Department, University of Minho, Campus de Azurém, 4800 - 058 \\ Guimarães, Portugal
}

*Corresponding author. Tel.: +351253 510271; fax: +351253510293

E-mail address: artur@det.uminho.pt

\begin{abstract}
Chronic non-healing skin wounds, such as leg ulcers and pressure sores, represent a major clinical problem and a financial burden for the health care systems. Chronic wounds are characterised by prolonged inflammatory phase that results in high levels of elastase, reactive oxygen species (ROS) and diminished growth factor activity. Under normal physiological conditions, elastase is a powerful host defence and its activity is regulated by endogenous inhibitors. The unrestrained elastase activity in chronic wounds may be tuned by exogenous active materials that inhibit elastase. Secretory leucocyte protease inhibitor, SLPI, is a potent endogenous inhibitor of elastase. Peptide fragments, KRCCPDTCGIKCL (Pep4) and KRMMPDTMGIKML (Pep4M), selected from SLPI primary structure were studied as potential elastase inhibitors. Kinetic studies performed for human neutrophil elastase (HNE) and porcine pancreatic elastase (PPE) in presence of these peptides revealed that both behave as uncompetitive and non-competitive inhibitors of HNE and PPE, respectively. The influence of ROS and albumin on Pep4 and Pep4M inhibitory activity towards elastase, reveals that this mixture increases the inhibitory activity of both peptides. These peptides were incorporated in hyaluronic acid hydrogels, to evaluate the possibility of being used as active compounds in a drug delivery system. Assessment of HNE and PPE activity in
\end{abstract}


the presence of these hydrogels formulations revealed a considerable decrease in enzyme activity. Although, only moderated elastase inhibition was observed, these peptides represent potential candidates for chronic wound applications, as there is no need for complete elastase inhibition in the normal wound healing process.

Key Words: Elastase; Inhibitor-peptides; Kinetic parameters; Reactive oxygen species; Hyaluronic acid hydrogels.

Abbreviations: SLPI, secretory leukocyte protease inhibitor; HNE, human neutrophil elastase; PPE, porcine pancreatic elastase; MMP, matrix metalloproteinase; ROS, reactive oxygen species; RNS, reactive nitrogen species; Pep4, Peptide 4; Peptide 4, KRCCPDTCGIKCL; Pep4M, Peptide 4 Modified; Peptide 4 Modified, KRMMPDTMGIKML; $p$-NA, $p$-Nitroaniline; DTT, DL-Dithiothreitol.

\section{INTRODUCTION}

Wound healing is a complex biological process that ultimately results in restoration of tissue integrity ${ }^{1}$. This complex cascade of events starts from the moment of injury and continues for varying periods of time depending on the severity of the wounding ${ }^{2}$. Physiologically, this process can be categorized in three different phases: inflammatory (consisting of the establishment of homeostasis and inflammation); proliferative (consisting of granulation, contraction and epithelialization) and remodelling (that ultimately determines the strength and appearance of the healed tissue) ${ }^{2-6}$. However, wound healing is not always a linear process and it can progress forward and backward through the different phases, depending on various intrinsic and extrinsic factors ${ }^{3}$. Normal wound healing is a carefully controlled balance of destructive processes necessary to remove damaged tissue and repair processes which lead to new tissue formation ${ }^{7}$. Chronic non-healing wounds, such as pressure sores, diabetic foot ulcers, venous leg ulcers and other delayed wounds, have failed the progress through the normal stages of healing and therefore enter in a state of pathologic inflammation ${ }^{7,8}$.

Exudates from chronic non-healing wounds contain elevated levels of proteolytic enzymes like elastase ${ }^{9}$, matrix metalloproteinase (MMP) ${ }^{10}$ and plasmin ${ }^{11,12}$, reactive oxygen species (ROS) ${ }^{7,9,13}$ and reactive nitrogen species (RNS) ${ }^{13}$. The excessive 
production of elastase and other proteolytic enzymes by polymorphonuclear granulocytes leads to considerable reduction on the amounts of growth factors and proteinase inhibitors, resulting in an imbalance between degradation and remodelling processes ${ }^{13}$. In addition, the overproduction of ROS (such as, hydrogen peroxide $\left(\mathrm{H}_{2} \mathrm{O}_{2}\right)$, hypochlorous acid $(\mathrm{HOCl})$, hydroxyl radicals $(\mathrm{HO} \bullet)$, superoxide anions $\left.\left(\mathrm{O}_{2}{ }^{-}\right)\right)$ and RNS species (like nitric oxide (NO) and its peroxynitrite derivatives) results in an imbalance oxidant/antioxidant status in chronic wounds ${ }^{13}$. ROS and RNS play an important role in the normal wound healing process by killing invading microorganisms and therefore their presence is necessary in the early stages of wound healing to initiate the inflammatory response ${ }^{7,13,14}$. At low concentrations $(0.01-1 \mu \mathrm{M})$ oxidizing species such as hydrogen peroxide $\left(\mathrm{H}_{2} \mathrm{O}_{2}\right)$ have been shown to have a positive effect in acute wound repair, stimulating fibroblast proliferation ${ }^{7}$. However, their continuous presence is thought to be detrimental to the healing process ${ }^{15}$. Studies have shown that reactive oxygen species can induce matrix metalloproteinase production and in severe cases can result in tissue necrosis and permanent tissue damage ${ }^{7,13}$. Therefore, decreasing the levels of ROS/RNS species and elastase in the wound fluid seems a suitable way to release the wound from the inflammatory phase and thus progress the normal wound healing process.

Currently, most of the dressings have been designed to create a moist wound healing environment, which allows the wound fluids and growth factors to remain in contact with wound and thus accelerating wound healing ${ }^{16}$. In most of the cases, these dressings are based on polymeric hydrogels, which are three-dimensional networks that swell quickly by imbibing a large amount of water. These materials closely resemble the living tissues because of their high water contents, soft and rubbery consistency and their biocompatibility to tissue and blood ${ }^{16}$. Hydrogels are prepared from synthetic and natural polymers. Hyaluronic acid (HA) is a naturally occurring polymer associated with various cellular processes involved in wound healing ${ }^{17}$. The physiological activity of hyaluronic acid (HA) polymers and oligomers makes it a promising and ideal material for wound dressing applications. HA can be tailored to a specific application but still retains its natural biocompatibility, biodegradability and lack of immunogenicity ${ }^{18}$.

In a previous work ${ }^{19}$, we have reported the application of an on-off switch, based on the reversible process of phosphorylation/dephosphorylation, to control the inhibitory 
activity of small peptides towards elastase, in wound dressing applications. These peptides were selected from the antimicrobial domain of an endogenous elastase inhibitor, secretory leucocyte protease inhibitor (SLPI). These tridecamer peptides, Pep4 (KRCCPDTCGIKCL) and Pep4M (KRMMPDTMGIKML), revealed differential elastase inhibitory activity for the non-phosphorylated (high inhibition) and phosphorylated (low inhibition) form. The biomatrices ${ }^{20,21}$ proposed to enclose this system were protease degradable materials. The biomatrix disruption was triggered by wound medium elastase, followed by active material release (inhibitor-peptides) and then in a later stage protein kinase release. The protein kinase promotes the inhibitors phosphorylation and subsequence reduction on peptides inhibitory activity towards elastase. This approach although promising required the control of several variables, such as ATP levels at wound site, peptides and protein kinase loadings and degradation rates, biomatrix degradation rate, among others.

In this article, an alternative wound dressing system is proposed, A model drug delivery system, based in hyaluronic acid hydrogels (HA), has been used to test the applicability of these 13-mer peptides, Pep4 and Pep4M, in wound dressing applications. In addition, a complete study of the kinetic parameters obtained for the substrate hydrolysis by PPE and HNE in presence of both peptides, is also reported herein. Lastly, it is evaluated the effect of the ROS, that are present in high concentrations in chronic non-healing wounds, on the inhibitory activity of the studied peptides towards PPE.

\section{MATERIALS AND METHODS}

\section{Reagents}

The inhibitor-peptides KRCCPDTCGIKCL (Pep4) and KRMMPDTMGIKML (Pep4M) were tailor-made by JPT Peptide Technologies GmbH (Berlin, DE) and the non-peptide inhibitor, elastatinal (BML-PI103) was obtained from Enzo Life Sciences (Farmingdale, NY, US). Porcine pancreatic elastase (E1259) and the chromogenic substrate $\mathrm{N}$ Succinyl-(Ala) 3 - $p$-nitroanilide (S4760), were purchased from Sigma Chemical Co (St. Louis, MO, US). Human neutrophil elastase (324681) and the colorimetric substrate MeO-Succinyl-(Ala) $)_{2}$-Pro-Val-p-nitroanilide (324696) were obtained from Calbiochem (Darmstadt, DE). Reactive oxygen species (ROS) were prepared using hydrogen
João Carlos Marcos 6/9/12 11:44

Deleted: has been propose

João Carlos Marcos 6/9/12 11:44

Deleted: $d$ to the previous reported

oão Carlos Marcos 6/9/12 11:45

Deleted: has also been

João Carlos Marcos 6/9/12 11:46

Deleted: was also

João Carlos Marcos 6/9/12 11:48

Deleted: whether 
peroxide $(30 \%(\mathrm{w} / \mathrm{v}), 121076)$ from Panreac (Barcelona, ES), sodium nitrite (10256) from BDH (Poole Dorset, UK), manganese dioxide (105957) from Merck (Darmstadt, DE), sodium hypochlorite solution (42,504-4), xanthine (X0626), xanthine oxidase (X4500) and cytochrome c, from bovine heart (C2037) from Sigma Chemical Co (St. Louis, MO, US). Albumin from bovine serum (A3983) used in the ROS assays was also supplied by Sigma Chemical Co (St Louis, MO, US). Hyaluronic acid (1.7 million Daltons) supplied from Contipro C a. s. (Dolní Dobrouč, CZ), was used in the hydrogels formulations.

All reagents were acquired with analytical grade and used as supplied. The aqueous solutions were prepared in deionized water and stored at $4^{\circ} \mathrm{C}$.

The inhibition kinetic assays were performed in microplate format, using 96 wells microplates (F96) from Nunc (Rochester, NY, US).

The ROS and HA hydrogel assays were performed in one milliliter quartz cells (108000-10-40) from Hellma (Müllheim, DE).

The reagents used in the electrophoresis (SDS-PAGE) assay, acrylamide/bisacrylamide solution $\quad(37.5: 1) \quad$ at $40 \% \quad(161-0148), \quad N, N, N^{\prime}, N^{\prime}$-tetra-methyl-ethylenediamine (TEMED, 161-0800), ammonium persulfate (APS, 161-0700) and broad range protein marker (Precision Plus Protein Standards, 161-0373) were purchased to Bio-Rad Laboratories (Hercules, CA, US).

\section{Elastase Inhibition Kinetics}

Inhibition kinetics for the synthetic peptides (Pep4 and Pep4M) and elastatinal were determined using $N$-succinyl-Ala 3 - $p$-nitroanilide as PPE substrate, in $100 \mu \mathrm{M}$ Tris $/ \mathrm{HCl}$, pH 8.0 and MeO-Succinyl-Ala 2 -Pro-Val-p-nitroanilide as HNE substrate, in $200 \mu \mathrm{M}$ Phosphate Buffer, $\mathrm{pH} 8.0^{22}$. The assays were carried out at room temperature, during 30 minutes, in 96 wells microplates (F96, Nunc, Rochester, NY, US) and monitored at 410 nm, using a UV-Vis Varian, Cary 50 reader (Palo Alto, CA, US).

Briefly, an elastase solution $(15 \mu \mathrm{L})$ preincubated (for five minutes) with the inhibitor Deleted: microtiter plates ( João Carlos Marcos 6/9/12 15:00 solution $(15 \mu \mathrm{L})$ was added to a total assay mixture containing buffer and substrate $(270$ Deleted: $\mu \mathrm{L})$. Nine different substrate concentrations between 0.1 and $3.0 \mathrm{mM}$ were used for PPE 
(0.3 units $/ \mathrm{mL}$ ) and between 0.1 and $2.5 \mathrm{mM}$ for $\mathrm{HNE}(0.5$ units $/ \mathrm{mL})$. Inhibitors concentration used in the current assays ranged between 1 and $64 \mu \mathrm{M}$. These assays were all performed in triplicate and represented as mean $\pm \mathrm{SD}$.

Initial rate data was fitted to Michaelis-Menten equation using a non-linear regression analysis (OriginPro 8.5 Software) and also fitted to a Direct Linear Plot (Hyper32.exe, Version 1.0.0, 2003).

Preceding these enzymatic assays, enzyme and inhibitor incubation times were determined performing kinetic assays using a constant concentration of inhibitor and incubation periods of 5, 15 and 30 minutes. The obtained hyperbolic curves were superimposed and therefore the lowest incubation time ( 5 minutes) was employed for all the inhibitors tested herein.

Prior to the kinetic assays, the microplate well pathlength $(l=0.82 \mathrm{~cm})$ was determined using $p$-nitroaniline solutions ranging from 20 to $100 \mu \mathrm{M}$, in a total volume of $300 \mu \mathrm{L}$ and using $8.8 \mathrm{mM}^{-1} \mathrm{~cm}^{-1}$ as the molar extinction coefficient of $p$-nitroaniline at $410 \mathrm{~nm}$ 23-25.

The microplates used in the current assays were blocked with albumin solution (BSA, 1 $\mathrm{mg} / \mathrm{mL}$ ) overnight, followed by three washes of thirty minutes with buffer (Tris/ $\mathrm{HCl}$ or Phosphate buffer, $\mathrm{pH} 8.0$ ). This pretreatment with BSA was applied to the microplates to avoid UV radiation absorption by the microplate material.

\section{Effect of ROS on Elastase Activity - In Vitro Study}

Preparation of Reactive Oxygen Species (ROS). The influence of reactive oxygen species (hydrogen peroxide $\left(\mathrm{H}_{2} \mathrm{O}_{2}\right)$, hypochlorous acid $(\mathrm{HClO})$, peroxynitrite $\left(\mathrm{ONOO}^{-}\right)$ and superoxide $\left.\left(\mathrm{O}_{2} \bullet^{-}\right)\right)$on the inhibitor-peptides activity towards elastase was evaluated using normal physiological levels of these species $(100 \mathrm{mM}, 100 \mu \mathrm{M}, 500 \mu \mathrm{M}$ and 400 $\mu \mathrm{M}$, respectively, ${ }^{26}$. The preparation of these reactive oxygen species (ROS) was performed as described herein.

Hypochlorous acid was prepared immediately before use by adding diluted sulphuric acid to sodium hypochlorite till pH 6.2 is reached (Eq. 1) ${ }^{27-29}$. The concentration of 
$\mathrm{HClO}$ used was $100 \mu \mathrm{M}$, which was determined from its molar absorptivity of $100 \mathrm{M}^{-}$ ${ }^{1} \mathrm{~cm}^{-1}$ at $235 \mathrm{~nm}^{26,30,31}$.

$$
\mathrm{OCl}^{-}+\mathrm{H}^{+} \leftrightarrow \mathrm{HOCl}
$$

Peroxynitrite was obtained as previously reported by Hughes and co-workers ${ }^{32}$. Briefly, $100 \mathrm{~mL}$ of ice-cold hydrochloric acid $(0.6 \mathrm{M}) /$ hydrogen peroxide $(0.7 \mathrm{M})$ solution was poured into a stirred iced solution of sodium nitrite $(0.6 \mathrm{M}, 100 \mathrm{~mL})$ followed immediately by sodium hydroxide (1.5 mM, $100 \mathrm{~mL}$ ) (Eq. 2). To increase the peroxynitrite yield in the reaction, all the solutions were mixed as fast as possible. The excess of hydrogen peroxide, used to minimize nitrite contamination, was removed from the peroxynitrite solution by adding manganese dioxide $(6 \mathrm{mg} / \mathrm{mL})$ and keeping the solution at $4^{\circ} \mathrm{C}$ for 30 minutes ${ }^{33}$. The solution was then filtered in cellulose filters (three times) and then in nylon membrane filters with pore size of $0.2 \mu \mathrm{M}$ (one time). The obtained solution was then frozen at $-20^{\circ} \mathrm{C}$ overnight, resulting in the formation of a top yellow layer due to freeze fractionation of peroxinitrite. This yellow top layer was scraped and stored at $-20^{\circ} \mathrm{C}$, for further studies. The concentration of peroxynitrite was determined by measuring its absorbance at $302 \mathrm{~nm}$ in $1 \mathrm{M}$ sodium hydroxide $(\mathcal{E}=1670$ $\left.\mathrm{M}^{-1} \mathrm{~cm}^{-1}\right)^{32,34-37}$.

$$
\mathrm{H}_{2} \mathrm{O}_{2}+\mathrm{NO}_{2}^{-} \rightarrow \mathrm{ONOO}^{-}+\mathrm{H}_{2} \mathrm{O}
$$

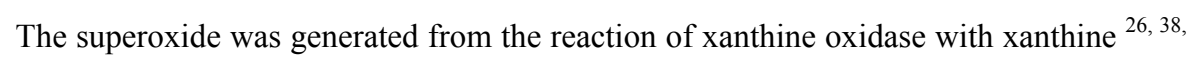
${ }^{39}$. Briefly, 1.05 units of xanthine oxidase were added directly to $23 \mathrm{~mL}$ of $2.1 \mathrm{mM}$ xanthine solution, previously prepared in PBS buffer, $\mathrm{pH}$ 7.0. The enzymatic reaction was carried out for 1 hour at $37^{\circ} \mathrm{C}$ in a $25 \mathrm{~mL}$ conical flask with stirring. The concentration of $\mathrm{O}_{2}{ }^{-}$was determined by observing the reduction of cytochrome $\mathrm{c}(0.8$ $\mathrm{mM})$ at $550 \mathrm{~nm}$, using an absorption coefficient of $2.1 \times 10^{4} \mathrm{M}^{-1} \mathrm{~cm}^{-1} 40,41$.

Assessment of Elastase Activity in presence of ROS. Prior to elastase activity assay, the inhibitors (20 $\mu \mathrm{M}$ Pep4, Pe4M and elastatinal) were incubated with each oxidant and oxidant plus albumin $(50 \mathrm{mg} / \mathrm{mL}$ of BSA), in equal proportions (volumes), at room temperature, for two hours ${ }^{26} 27$. Afterwards, these solutions were incubated with elastase for five minutes at room temperature, immediately before initiating the enzyme activity assay. 
Porcine Pancreatic Elastase activity was assayed spectrophotometrically by continuously measuring the rate of hydrolysis of the substrate N-succinyl-Ala-Ala-Ala$p$-nitroanilide to $p$-nitroaniline, at $410 \mathrm{~nm}^{42}$. Briefly, the reaction was initiated by the addiction of PPE ( 0.3 units $/ \mathrm{mL}, 33.3 \mu \mathrm{L})$ to a buffer solution $(100 \mu \mathrm{M}$ Tris/HCl, $\mathrm{pH} 8.0$, $933.3 \mu \mathrm{L})$ containing substrate $(4.4 \mathrm{mM}, 66.7 \mu \mathrm{L})$. Inhibitor experiments with and without oxidant treatment were performed under identical conditions. The reaction was carried out at room temperature, during 60 minutes, in a one mL quartz cell (108-00010-40, Hellma, Müllheim, DE) and monitored at $410 \mathrm{~nm}$ using an UV-Vis Shimadzu spectrophotometer (UV-2501PC, Kyoto, JP).

Study of the Reaction $B S A-H_{2} \mathrm{O}_{2}$ by Electrophoresis (SDS-PAGE). SDS-PAGE electrophoresis was used to follow the reaction between albumin (BSA) and hydrogen peroxide $\left(\mathrm{H}_{2} \mathrm{O}_{2}\right)$ and this assay was performed as described by Laemmli ${ }^{43}$. This reaction occurs in ROS assay, in which high concentrations of albumin and hydrogen peroxide were applied comparatively to what will be used herein. In this assay lower BSA (1.125 to $2.0 \mathrm{mg} / \mathrm{mL})$ and $\mathrm{H}_{2} \mathrm{O}_{2}(0.25$ to $4.0 \mathrm{mg} / \mathrm{mL})$ concentrations were employed, although the initial proportion between both components was kept. The reaction mixtures were incubated during two and twenty-two hours at room temperature. Diluted samples of BSA, BSA $+\mathrm{H}_{2} \mathrm{O}_{2}$ oxidant mixture and protein markers were loaded into 4\% stacking gel and further separated in 8 and 10\% resolving gel, under denaturing conditions. The gels were stained with Coomassie blue R-250 overnight and destained with methanol/acetic acid (40/7\% and 5/7\%) solutions.

\section{Elastase Activity Assay in the presence of HA Hydrogel Formulations}

Hydrogel Preparation. The hydrogel crosslinking procedure used herein has been previously outlined by J. W. Burns and co-workers ${ }^{44}$. Briefly, in order to obtain an autocrosslinked hyalorinic acid (HA) hydrogel ${ }^{45}, 100 \mathrm{mg}$ of HA was dissolved in 10 $\mathrm{mL}$ of deionized water. The $\mathrm{pH}$ of the aqueous solution was adjusted to 4.7 , using $\mathrm{HCl}$ $1 \mathrm{M}$ and then casted into $35 \mathrm{~mm}$ diameter petri dishes (83.1800.002, Sarstedt, DE). Subsequently, the petri dishes were frozen at $-20^{\circ} \mathrm{C}$ for 2.5 days and then thawed at $25^{\circ} \mathrm{C}$. Afterwards, the hydrogels were dehydrated in an incubator shaker (Infors HT - 
Minitron, Bottmingen, $\mathrm{CH}$ ) at $35^{\circ} \mathrm{C}$ during approximately 10 hours. Then the thickness of the obtained films (Figure 1) was determined using a digital micrometer (series 293, Mitutoyo, Kanagawa, JP).

Water Content and Thickness of HA Hydrogels. To determine the water content, the dehydrated HA hydrogels were weighed and then incubated in $4 \mathrm{~mL}$ of deionized water for 30 minutes. The water excess was removed and the hydrogels re-weighed. The water content of the hydrogels was calculated according to equation 3

$$
\% \text { Water }=\frac{W h-W d}{W h} \times 100
$$

where, Wh represents the weight of the hydrated hydrogel and Wd the weight of the dried film. The thickness of the HA films was determined using a digital micrometer (series 293, Mitutoyo, Kanagawa, JP). All measurements performed in this section were made in triplicate.

Elastase Activity Assay in HA Hydrogels. The dried HA films prepared in two sections before (Figure 1), were submerged in $2 \mathrm{~mL}$ of inhibitor solutions (Pep4, Pep4M or elastatinal), prepared in $200 \mu \mathrm{M}$ phosphate buffer, $\mathrm{pH}$ 8.0. The inhibitor concentrations selected to hydrate the HA films were those that highly inhibits elastase in the kinetic assays. Therefore 1, 4 and $64 \mu \mathrm{M}$ concentrations of Pep4, Pep4M and elastatinal ${ }^{19}$ were used in the PPE assay and 32,1 and $64 \mu \mathrm{M}$ concentrations in HNE assays, respectively. HA hydrogels were also hydrated with $2 \mathrm{~mL}$ of $200 \mu \mathrm{M}$ phosphate buffer, $\mathrm{pH} 8.0$, to use as control in the elastase enzymatic assay. These hydrogels, with a final $\mathrm{pH}$ of 8.0, were allowed to incubate for 30 minutes at room temperature.

PPE and HNE activity was assayed spectrophotometrically using N-succinyl-Ala-AlaAla- $p$-nitroanilide and MeOSuccynyl-Ala-Ala-Pro-Val- $p$-nitroanilide as respective substrates. Briefly, the HA hydrated hydrogels (described in this section) were incubated in $1 \mathrm{~mL}$ of elastase solution (36 munits $/ \mathrm{mL}$ of PPE and HNE) ${ }^{46}$ for 1 hour at room temperature ${ }^{46-49}$. The elastase supernatant $(933.3 \mu \mathrm{L})$ from each hydrogel was assayed with the respective substrate $\left(66.7 \mu \mathrm{L}\right.$ of $\mathrm{N}-\mathrm{Suc}-\mathrm{Ala}_{3}-p-\mathrm{NA}(4.4 \mathrm{mM})$ and MeOSuc-Ala 2 -Pro-Val- $p$-NA $(3.0 \mathrm{mM}))$, for five minutes at room temperature. The

\section{João Carlos Marcos 6/9/12 15:17}

Comment [1]: Tenho dúvidas relativamente a esta designação. Provavelmente ficará melhor mUnits 
spectrophotometric measurement of the release of $p$-nitroaniline from the enzymatic hydrolysis of the substrates was performed at $410 \mathrm{~nm}$ in a Shimadzu spectrophotometer (UV-2501PC, Kyoto, Japan) using one mL quartz cuvettes (Hellma, Müllheim, DE).

\section{RESULTS AND DISCUSSION}

The tridecamer peptide Pep4 primary structure, KRCCPDTCGIKCL (Figure 2), was selected from the natural human neutrophil elastase (HNE) inhibitor, secretory leucocyte protease inhibitor (SLPI). This peptide structure was picked from the inner part of an extended planar spiral in the N-terminal domain of SLPI ${ }^{50}$. Due to the high cysteine content of this tridecamer peptide, a mutation of this peptide was also designed having replaced the cysteine residues for a less reactive residue, methionine, and therefore generating a second 13-mer peptide Pep4M, KRMMPDTMGIKML.

\section{Elastase Inhibitor Kinetic Assays}

Enzymatic kinetics of PPE and HNE were studied in the presence of the inhibitorpeptides (Pep4 and Pep4M) and elastatinal (non-peptidic elastase inhibitor used as control) ${ }^{51-53}$. Kinetic data shown in Michaelis-Menten plots for Pep4 (Figure 3 a) and c)) reveal a good fit of the experimental data to a hyperbole. No relevant differences have been observed in data analysed using Michaelis-Menten plot and the direct linear plot (data not shown). Michaelis-Menten plot for PPE and HNE in presence of Pep4 (Figure 3 a) and c)), reveals no linear relationship between the inhibitor concentration and the resulting kinetic parameters, $K_{m}^{a p p}$ and $V_{\max }^{a p p}$ (see Table I). However, there is a general tendency within the obtained values of $K_{m}^{a p p}$ and $V_{\max }^{a p p}$ for the different inhibitor concentrations relatively to the $\mathrm{K}_{\mathrm{m}}$ and $\mathrm{V}_{\max }$ values (Table I). For PPE, $K_{m}^{a p p}$ remain constant and $V_{\max }^{a p p}$ decreases comparatively to $\mathrm{V}_{\max }$, while for HNE, $K_{m}^{a p p}$ and $V_{\max }^{a p p}$ decrease comparatively to $\mathrm{K}_{\mathrm{m}}$ and $\mathrm{V}_{\max }$, respectively. A possible explanation for the irregular behaviour might stand in the peptide structure. Pep4 contains four cysteine residues that might form intramolecular and/or intermolecular disulfide bridges, leading potentially to some form of oligomerization of the peptide in solution. The potential formation of small polypeptides via disulfide bridges may induce differential inhibitory activity of this peptide towards elastase, which is reflected in the obtained kinetic 
parameters. This hypothesis was tested performing a kinetic assay of PPE inhibition by Pep4 $(8 \mu \mathrm{M})$ in presence and absence of a reducing agent (DL-Dithiothreitol, 1-5 mM). However, the Michaelis-Menten plot revealed no significant differences between Pep4 and Pep4+DTT hyperbolic curves (data not shown). Consequently, no alteration of the kinetic parameters, $K_{m}^{a p p}$ and $V_{\max }^{a p p}$, were observed when Pep4 with and without DTT were used as elastase inhibitor (Figure 4). A mutated peptide (Pep4M) where the cysteine residues were replaced by the methionine residues was also used to eliminate the possibility of occurring disulfide bridges intra and inter-residues, which might alter the behaviour of the peptide in solution. Kinetic assays using Pep4M as inhibitor and PPE and HNE as enzyme have been performed (Figure 5 and Table II). In this assays, a similar behaviour to Pep4 has been obtained for Pep4M. No linear relation was observed between the inhibitor concentration and the attained kinetic parameters. As in the previous peptide, for PPE, $K_{m}^{a p p}$ remain almost constant (except for the [I] $=2 \mu \mathrm{M}$ assay) and $V_{\max }^{a p p}$ decreases comparatively to $\mathrm{V}_{\max }$, while for $\mathrm{HNE}, K_{m}^{a p p}$ and $V_{\max }^{a p p}$ decrease comparatively to $K_{m}$ and $V_{\max }$, respectively. Kinetic studies on PPE using these inhibitor-peptides and different enzyme concentrations, substrate concentration range and also other buffer solution $(200 \mu \mathrm{M}$ phosphate buffer, $\mathrm{pH} 8.0)$ have been tested, although the same behaviour have been obtained. In order to have a control in these enzymatic assays, an elastase inhibitor selected from literature, elastatinal ${ }^{54}$, was assessed with PPE and HNE. For this inhibitor a direct correlation between inhibitor concentration and the level of enzyme inhibition has been achieved, for both enzymes (PPE and HNE). Elastatinal behaves as a competitive inhibitor for both enzymes, PPE and HNE. The enzymes (E) and inhibitor (I) react according to the biomolecular and reversible mechanism described in Figure 6 a). Hence, the competitive inhibition constants, $K_{i c}$, were deduced from equation 4 and the obtained $K_{i c}$ values collected in Table III.

$$
K_{m}^{a p p}=K_{m}\left(1+\frac{i}{K_{i c}}\right)
$$

PPE inhibition by Pep4 and Pep4M was analysed considering that elastase and the inhibitor-peptides follow a mixed inhibition mechanism, described in Figure 6 b). The analysis of direct linear plots (Figure 3 and 5) and the kinetic parameters resumed in Table I and II, for PPE inhibition by Pep4 and Pep4M, reveal that $K_{m}^{a p p}$ remain constant and $V_{\max }^{a p p}$ decreases comparatively to $\mathrm{V}_{\max }$ and that alpha/alpha' $\left(\alpha / \alpha^{\prime}\right)$ ratio is 
approximately one. Thus, PPE inhibition by both inhibitors-peptides is a particular case of the mixed inhibition, the non-competitive inhibition. In this inhibition type, the inhibition constants, $\mathrm{K}_{\mathrm{ic}}$, and $\mathrm{K}_{\mathrm{iu}}$ are similar and consequently $\mathrm{K}_{\mathrm{m}}$ is equal to $K_{m}^{a p p}$. The inhibitions constants were determined from equation 5 and the respective values comprised in Table I and II.

$$
V^{a p p}=\frac{V}{1+\frac{i}{K_{i u}}}
$$

The inhibition constants, $\mathrm{K}_{\mathrm{ic}}$ and $\mathrm{K}_{\mathrm{iu}}$, increased with the inhibitor concentration, which it is not expected to occur. The inhibition kinetics of HNE by Pep4 and Pep4M was evaluated considering that enzyme and inhibitors follow an uncompetitive inhibition. According to the direct linear plots (Figure $3 \mathrm{~b}$ ) and d) and Figure $5 \mathrm{~b}$ ) and c)) and to the kinetic parameters included in Table I and II, for HNE inhibition by Pep4 and Pep4M, it is possible to state that $K_{m}^{a p p}$ and $V_{\max }^{a p p}$ decrease comparatively to $\mathrm{K}_{\mathrm{m}}$ and $\mathrm{V}_{\max }$, respectively. The ratio $\frac{V^{a p p}}{K_{m}^{a p p}}$ is constant for all inhibitor concentrations and identical to $\frac{V_{\max }}{K_{m}}$. For this inhibition type, the inhibition constant, $\mathrm{K}_{\mathrm{iu}}$, was determined using equation 5 and the obtained values were included in Table I and II.

The inhibition constant, $\mathrm{K}_{\mathrm{iu}}$, increase with the inhibitor concentration and as previously emphasized this situation might be due to the absence of a direct relation between the inhibitor concentration applied and the levels of elastase inhibition achieved. Therefore, to better elucidate the behaviour of both peptides as elastase (PPE and HNE) inhibitors, a plot comprising the $\mathrm{V}_{\max } / \mathrm{K}_{\mathrm{m}}$ ratio versus the inhibitor concentration was drawn (Figure 7). In this plot, for all the enzyme and peptide combinations the obtained result was nearly a horizontal straight line. In the HNE assays, this was the expected behaviour once in the uncompetitive inhibition the ratio $V_{\max } / K_{m}$ should remain unchanged for all the inhibitor concentrations. In opposition, in the PPE assays a decreasing line was expected, once in the mixed inhibition type the ratio $V_{\max } / K_{m}$ might decrease with the inhibitor concentration.

In a previous work we have reported that Pep4 and Pep4M behave as slow velocity substrates of elastase (PPE) that at low concentrations function as elastase inhibitors ${ }^{19}$. Even so, comparing the inhibition constant, $\mathrm{K}_{\mathrm{ic}}$, for PPE in presence of Pep4 (0.46-5.00 
$\mu \mathrm{M})$, Pep4M (0.54-1.67 $\mu \mathrm{M})$ and elastatinal $(5.2 \pm 2.9$ and $5.8 \pm 1.8 \mu \mathrm{M})$, it is thus possible to state that at lower inhibitor-peptide concentrations (lower than $8 \mu \mathrm{M}$ ) comparable values of $\mathrm{K}_{\mathrm{ic}}$ can be achieved for these inhibitor-peptides relatively to elastatinal. Moreover, according to these studies Pep 4 and Pep4M behaved as mixed PPE inhibitors, which mean that both peptides bind to the free enzyme (E) to give an EI complex or to the enzyme-substrate complex (ES) to give a complex ESI ${ }^{55}$. In this particular case, as the $\alpha / \alpha$ ' ratio is approximately one, these inhibitors bind in equal proportion both to the free enzyme and to the enzyme-substrate complex. However, these peptides behaved as uncompetitive HNE inhibitors, which means that these inhibitors only bind to the enzyme-substrate complex (ES) and do not to bind to the free enzyme (E). The current study revealed that for these elastase inhibitor-peptides, Pep 4 and Pep4M, the PPE does not seems an appropriate enzymatic model for HNE, once no similar behaviour was observed for both enzymes in presence of these peptides.

\section{ROS Effect on Elastase Activity}

In humans, the endogenous antiproteases are known to be inactivated from stimulated neutrophils ${ }^{26}$. For instance, alpha-1 Proteinase Inhibitor ( $\left.\alpha 1-\mathrm{PI}\right)$ an endogenous elastase inhibitor responsible for $90 \%$ of elastase inhibition in human serum, has been reported to be inactivated by leukocyte derived oxidants, including superoxide $\left(\mathrm{O}_{2} \bullet^{-}\right)^{56}$, hydrogen peroxide $\left(\mathrm{H}_{2} \mathrm{O}_{2}\right)^{27,56}$, hypochlorous acid $(\mathrm{HClO})^{27,57,58}$ and hydroxyl radical $(\mathrm{HO} \bullet)^{59}$.

Huang and co-workers ${ }^{26}$ have reported a family of trifluoromethyl ketone elastase inhibitors, which resist superoxide, hypochlorous acid, hydrogen peroxide, hydroxyl radical and peroxinitrite mediated degradation. They have determined the stability of each inhibitor in the presence of superoxide, hypochlorous acid, hydrogen peroxide, hydroxyl radical and peroxinitrite, performing an incubation of two hours at $37^{\circ} \mathrm{C}$ and then measuring the elastase activity, for one hour, in presence of the inhibitor-oxidant mixture. Wasil and co-works ${ }^{27}$ have performed a similar study but they have added albumin to the inhibitor-oxidant mixture, which reveal to have a striking protective effect on the inhibitor. Both studies seemed relevant and of major importance, thus we have extended these studies to our current work. Therefore, Pep4, Pep4M and elastatinal $(20 \mu \mathrm{M})$ were incubated with hydrogen peroxide $\left(\mathrm{H}_{2} \mathrm{O}_{2}, 100 \mathrm{mM}\right)$, hypochlorous acid 
$(\mathrm{HClO}, 100 \mu \mathrm{M})$, peroxinitrite $\left(\mathrm{ONOO}^{-}, 500 \mu \mathrm{M}\right)$ and superoxide $\left(\mathrm{O}_{2}{ }^{-}, 400 \mu \mathrm{M}\right)$ and elastase (PPE) activity measured (Figure 8). The inhibitors concentration tested in this assay does not correspond to the concentration that mostly inhibits PPE. It has been used the same concentration for all inhibitors in order to establish a comparative study. In Figure $8 \mathrm{c}$ ) elastatinal reveals a considerable decrease in its inhibitory capacity towards elastase, due to the presence of ROS. When $\mathrm{O}_{2}{ }^{-}, \mathrm{HClO}, \mathrm{H}_{2} \mathrm{O}_{2}$ and $\mathrm{ONOO}^{-}$, were used as oxidant the inhibitory activity of elastatinal decreased between 14.0 and $39.3 \%$. In presence of albumin (BSA), the inhibitory capacity of elastatinal increased slightly for $\mathrm{H}_{2} \mathrm{O}_{2}$, $\mathrm{ONOO}^{-}$and $\mathrm{O}_{2}{ }^{-}$and increased considerably for $\mathrm{HClO}$, almost nullifying this ROS effect. This data is in accordance with a previous study ${ }^{27}$, in which was reported that the presence of albumin, in concentrations lower than physiological concentrations, was able to completely inhibit inactivation of $\alpha 1-\mathrm{PI}$ by $\mathrm{HClO}$. Presumably, albumin reacts with $\mathrm{HClO}$ and preferentially scavenges this radical. Therefore, albumin reveals substantial antioxidant activity by scavenging $\mathrm{HClO}^{27}$.

In Figure 8 b), Pep4M was also assayed with elastase in presence of the oxidant species $\mathrm{H}_{2} \mathrm{O}_{2}, \mathrm{HClO}$, $\mathrm{ONOO}^{-}$and $\mathrm{O}_{2} \bullet^{-}$, revelling an unchangeable inhibitory behaviour in presence of these oxidants, with the exception of the peroxynitrite assay. In this particular case, the reduction of Pep4M inhibitory activity might be straightly related with the oxidation methionine residues (to methionine sulfoxide) at its catalytic centre, rendering to this peptide a decrement in its activity or even inactivation, in resemblance to what occur to $\alpha 1$-PI ${ }^{57,58,60-62}$, SLPI ${ }^{63,64}$ and $\alpha 2$-macroglobulin ${ }^{65,66}$ in presence of reactive oxygen species. When albumin is added to the reaction mixture, the inhibitory capacity increases considerably to values lower than those found in the inhibitor assay (approximately 80\%). Thus, albumin in this case protects the inhibitor-peptide (Pep4M) from ROS inactivation but also increases its inhibitory activity.

The same study was performed for Pep4 (Figure 8 a)), revealing that the presence of $\mathrm{O}_{2} \bullet^{-}$decreased his inhibitory activity and increased when albumin is added to the reaction mixture, similarly to what has been shown in Pep4M study. Although, when $\mathrm{H}_{2} \mathrm{O}_{2}$, $\mathrm{HClO}$ and $\mathrm{ONOO}^{-}$were used as oxidants, the inhibitory capacity of Pep4 increased, instead of decreasing, as it has occurred for the other two inhibitors (Pep4M and elastatinal). The addition of albumin to the reaction medium increased even more the inhibitory activity of Pep4, especially when $\mathrm{H}_{2} \mathrm{O}_{2}$, and $\mathrm{ONOO}^{-}$were used as 
oxidants. In the case of radical $\mathrm{HClO}$, the presence of albumin decreased slightly the inhibitory activity of Pep4.

A possible explanation for these results might stand in the structural differences between these two inhibitor-peptides, Pep4 and Pep4M. Pep4M comprise four methionine residues, while Pep4 contains four cysteine residues that provide exposed free sulfhydryl groups $(\mathrm{SH})$ that are very reactive and potential targets for radical attack.

With respect to proteins, the thiol group of cysteinyl side chains is susceptible to a number of oxidative modifications, for instance, the formation of inter- or intramolecular disulfides between protein thiols (protein (P)-S-S-P) or between protein thiols and low-molecular-weight thiols such as glutathione (P-S-SG), the oxidation to sulfenic $(\mathrm{P}-\mathrm{SOH})$, sulfinic $\left(\mathrm{P}-\mathrm{SO}_{2} \mathrm{H}\right)$, and sulfonic $\left(\mathrm{P}-\mathrm{SO}_{3} \mathrm{H}\right)$ acid and S-nitrosylation (P-S-NO). These modifications can alter the function of numerous proteins that contain cysteines of structural importance, within their catalytic centers or as part of proteinprotein interaction interfaces ${ }^{67-70}$.

Thus, the $\mathrm{H}_{2} \mathrm{O}_{2}$ (or other ROS) attack to the thiol side chain (-SH) of cysteine residues in Pep4, might involve the formation of dissulphide bridges (S-S) or the $-\mathrm{SH}$ groups might be oxidized to sulphenic acid (-SOH) and this can be further oxidized to sulphinic acid $\left(-\mathrm{SO}_{2} \mathrm{H}\right)$ or sulphonic acid $\left(-\mathrm{SO}_{3} \mathrm{H}\right){ }^{69}$. This structural modification might contribute to the increase of Pep4 inhibitory activity towards elastase comparatively to Pep4M, in this study.

In addition, to better understand the albumin (BSA) effect on the system elastaseinhibitor-peptide-ROS, some alterations have been introduced into the previous assay. The elastase enzymatic assay was performed in presence of Pep4M, Pep4M+ $\mathrm{H}_{2} \mathrm{O}_{2}$, Pep4M $+\mathrm{H}_{2} \mathrm{O}_{2}+\mathrm{BSA}$, Pep4+BSA, $\mathrm{H}_{2} \mathrm{O}_{2}+\mathrm{BSA}, \mathrm{H}_{2} \mathrm{O}_{2}$ and BSA, as shown in Figure 9. In the current assay, elastase activity decreases $13.1 \%, 20.4 \%$ and $36.5 \%$ for Pep4M, Pep4M $+\mathrm{H}_{2} \mathrm{O}_{2}$ and Pep4M $+\mathrm{H}_{2} \mathrm{O}_{2}+\mathrm{BSA}$, respectively. These results are in accordance João Carlos Marcos 6/9/12 16:23

presence of $\mathrm{H}_{2} \mathrm{O}_{2}$. When $\mathrm{H}_{2} \mathrm{O}_{2}$, Pep4M+BSA, BSA and $\mathrm{H}_{2} \mathrm{O}_{2}+\mathrm{BSA}$ were tested, the elastase activity decreased 24.0, 34.6, 35.2 and 39.7\%, respectively. Higher elastase inhibition was achieved when $\mathrm{H}_{2} \mathrm{O}_{2}+\mathrm{BSA}$ (60.3\%) is used, comparatively to Pep4M+BSA (65.4\%) and BSA (64.8\%). These results emphasized the fact that during 
the incubation of BSA with $\mathrm{H}_{2} \mathrm{O}_{2}$, an alteration might occur in BSA. To visualize these potential modification two techniques were used, mass spectrometry (MS) and SDSPAGE electrophoresis. Solutions of BSA $(50 \mathrm{mg} / \mathrm{mL})$ with $\mathrm{H}_{2} \mathrm{O}_{2}(100 \mathrm{mM})$ were incubated during two and twenty-two hours at room temperature. These solutions were prepared in $20 \%$ methanol and further introduced in a mass spectrometer (Thermo Electron Corporation Instrument, model Finnigan LXQ, Waltham, MA, US). The referred equipment has an upper detection limit of $2000 \mathrm{~m} / \mathrm{z}$ and within this range, only small fragments lower than $500 \mathrm{~m} / \mathrm{z}$ have been detected (data not shown). These fragments could in fact correspond to peptides formed by three to four amino acids residues resulting from BSA degradation by $\mathrm{H}_{2} \mathrm{O}_{2}$, although we do not attribute them the responsibility for the decrease on elastase activity in this assay. Therefore, another technique has been used to study the possible modification in BSA. Solutions of BSA $(0.125-2.0 \mathrm{mg} / \mathrm{mL})$ and $\mathrm{H}_{2} \mathrm{O}_{2}(0.25-4.0 \mathrm{mM})$ were prepared and samples of BSA and $\mathrm{BSA}+\mathrm{H}_{2} \mathrm{O}_{2}$, were incubated for two and twenty-two hours at room temperature and then loaded into 4\% stacking gel and further separated in 8\% resolving gel (Figure 10). Analysing these gels it was possible to state that no difference has been observed between the oxidant mixture $\mathrm{BSA}+\mathrm{H}_{2} \mathrm{O}_{2}$ incubated for two or twenty-two hours and the correspondent control of BSA. Moreover, it was performed another assay using a $10 \%$ resolving gel instead of $8 \%$ and using the lowest BSA and $\mathrm{H}_{2} \mathrm{O}_{2}$ concentrations in the oxidant mixture (Figure 11). With this assay we intent to visualize whether some low molecular degradation products were formed during the incubation period of BSA with $\mathrm{H}_{2} \mathrm{O}_{2}$. As in the previous gel, no differences were observed between the BSA samples and the respective oxidant mixtures. Therefore, no experimental explanation has been found for the fact that the presence of BSA enhances the inhibitory activity of the selected inhibitor-peptides. We envisage that the inhibitory capacity of the studied peptides, Pep4 and Pep4M, might be enhance when in close contact with chronic wound exudate, due to the presence of albumin in wound medium. Moreover, the peptide concentrations tested in this assay $(20 \mu \mathrm{M})$ is far from being the optimal concentration for each peptide to inhibit elastase. Thus, improved results are expected if $1 \mu \mathrm{M}$ of Pep4 or $4 \mu \mathrm{M}$ Pep $4 \mathrm{M}^{19}$ were used, instead of $20 \mu \mathrm{M}$. Therefore, this study demonstrates that the selected peptides are optimal candidates to be applied in wound dressing applications. 


\section{Elastase Activity in presence of HA Hydrogel Formulations}

Hyaluronic acid is a naturally occurring polymer, non-immunogenic, non-adhesive glycosaminoglycan that plays a prominent role in various wound-healing processes, such as angiogenesis ${ }^{71}$. Hyaluronic acid promotes early inflammation, which is critical for initiating wound healing, but then moderates later stages of this process, allowing matrix stabilization and reduction of long-term inflammation ${ }^{71}$. Furthermore, environments around human tissues involved in regeneration and wound healing are enriched with $\mathrm{HA}^{71}$. This cumulative evidence suggests that HA is an ideal candidate material for modulating wound healing. Therefore, HA hydrogels were used herein as wound dressings to enclose the inhibitors Pep4, Pep4M and elastatinal and further assayed their inhibitory capacity towards elastase (PPE and HNE). The Pep4, Pep4M and elastatinal concentrations used in the PPE assay were 1, 4 and $64 \mu \mathrm{M}$, while in the HNE assay were 32,1 and $64 \mu \mathrm{M}$, respectively. These concentrations correspond to the inhibitor concentrations that highly contribute to the decrease on elastase activity. To assess the ability of the HA-inhibitor (Pep4, Pep4M and elastatinal) hydrogels to lower elastase activity, HA hydrogels with and without inhibitor were placed in a solution of elastase at physiological levels (36 mUnits/mL of elastase in chronic wounds) ${ }^{46}$. The elastase activity present in the solution removed from the HA-inhibitor hydrogels were then compared with the activity of the solution from the HA without inhibitor (Figure 12). All HA hydrogel formulations containing inhibitor (Pep4, Pep4M or elastatinal) were found to inhibit elastase (PPE and HNE) activity. In the PPE assays, Pep4 and Pep4M induced an elastase activity decrease of 34.6 and $37.1 \%$, respectively. In the HNE assay, these peptides promoted a more considerable reduction on elastase activity, $67.9 \%$ for Pep4 and $72.5 \%$ for Pep4M. Elastatinal achieves, in both assays, the higher elastase inhibition, with inhibition levels of 97.6 and 83.1\% in the PPE and HNE assay, respectively. In the current study is shown a pattern, for both assays (PPE and HNE) the elastase inhibitory capacity obeys to an order: Pep4 $<$ Pep4M $<$ Elastatinal.

The HA films prepared for this assays were characterized in terms of water content and thickness. The water content of the HA hydrogels was determine as previously described, using equation 3. The water content average for the prepared HA hydrogels was $97.86 \pm 0.09 \%$. The thickness of the HA films was determined using a micrometer and the average thickness of the prepared films was $29 \pm 4 \mu \mathrm{m}$. 


\section{CONCLUSIONS}

In conclusion, the peptide fragments (Pep4: KRCCPDTCGIKCL and Pep4M: KRMMPDTMGIKML) selected from the endogenous elastase inhibitor secretory leucocyte protease inhibitor (SLPI), revealed to be moderate elastase inhibitors. According to the kinetic studies performed for HNE and PPE, these peptides behave as uncompetitive and non-competitive inhibitors of elastase, respectively. The studies on the influence of reactive oxygen species $\left(\mathrm{H}_{2} \mathrm{O}_{2}, \mathrm{HClO}\right.$, ONOO${ }^{-}$and $\left.\mathrm{O}_{2} \bullet^{-}\right)$and albumin (at physiological concentrations) in the inhibitory activity of Pep4 and Pep4M towards elastase revealed unexpected results. It was observed an increase in Pep4 inhibitory activity relatively to elastase when in presence of ROS. The incorporation of albumin (BSA) in the oxidant mixture also enhances the inhibitory capacity of both Pep4 and Pep4M towards elastase. The effect of albumin in the inhibitor peptide-oxidant mixture still remains unclear, however, it has been observed that ROS in the presence or absence of albumin do not influence negatively the inhibitory activity of the peptides towards PPE, in opposition to what occur with elastatinal. These results disclose an advantage of these peptides as elastase inhibitors for in vivo applications, once the presence of elevated levels of oxidant species are expected to occur under inflammatory conditions.

Hyaluronic acid (HA) or hyaluron has gained much attention due to its prominent role in wound healing as well as its natural biodegradability. HA based hydrogels are designated by some authors as biomaterials that heal, because these biomimetic materials are designed to promote natural healing and regeneration ${ }^{17}$. Thus, the HA hydrogels were chosen as our based material to incorporate the inhibitor-peptides and the resulting formulations evaluated as potential drug delivery system. These biomimetic materials were assessed in presence of HNE and PPE, at physiological concentrations (36 mUnits/mL of protease in chronic wounds) ${ }^{46}$ and these formulations have induced a significant decrease in the elastase activity.

According to Wiegand and co-workers, elastase concentration was found to be 10-times higher in chronic than in acute wound fluids $(2,480.01 \mathrm{ng} / \mathrm{mg}$ and $245.85 \mathrm{ng} / \mathrm{mg}$, respectively) ${ }^{72}$. These finds emphasized the fact that no complete elastase inhibition is needed for the wound healing progress. Therefore, the inhibitor-peptides reported herein that have revealed moderated elastase inhibition, represent potential candidates for

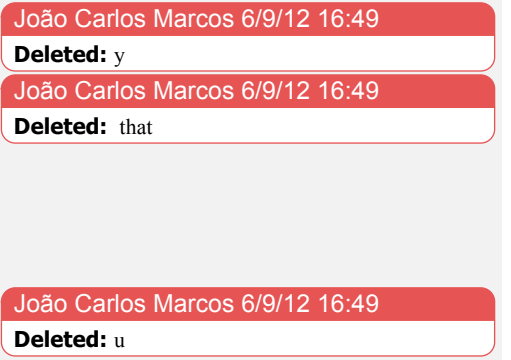

Deleted: u 
wound dressing applications. The incorporation of these inhibitor-peptides (Pep4 and Pep4M) at very low concentrations (less cost) in HA hydrogel films, which promote natural wound healing and regeneration, might be taken in consideration for future therapeutic applications.

\section{ACKNOWLEDGEMENTS}

The authors greatly acknowledge the European Project Lidwine - Multifunctional medical textiles for wound (e.g. Decubitus) prevention and improved wound healing for financial support, the Portuguese Foundation for Science and Technology for the Ph.D. fellowship SFRH/BD/36522/2007 and FEDER (European Fund for Regional Development)-COMPETE-QREN-EU for the financial support to the Research Centre, CQ/UM [PEst-C/QUI/UI0686/2011(FCOMP-01-0124-FEDER-022716].

The publication of these results was supported by the COST Action 868 . We would like to thank Professor Ana Campos (Chemistry Department, Minho University, Portugal) for supplying the hyaluronic acid employed in this study.

\section{João Carlos Marcos 6/9/12 17:00}

Comment [2]: Não foi a publicação que foi suportada pelo COST.

João Carlos Marcos 6/9/12 16:50

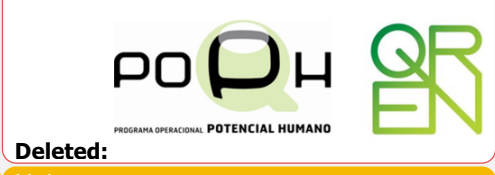

Formatted: Font:Times New Roman, 12 pt, Bold

\section{REFERENCES}

1. Young, A.; McNaught, C.-E. Surgery (Oxford) 2011, 29, 475-479.

2. Kondo, T. Legal Medicine 2007, 9, 109-114. 

866.

4. $\quad$ Enoch, S.; Leaper, D. J. Surgery (Oxford) 2008, 26, 31-37.

5. Enoch, S.; Leaper, D. J. Surgery (Oxford) 2005, 23, 37-42.

6. Braund, R.; Hook, S.; Medlicott, N. J. Current Drug Delivery 2007, 4, 195-204.

7. Cullen, B.; Watt, P. W.; Lundqvist, C.; Silcock, D.; Schmidt, R. J.; Bogan, D.; Light, N. D. The International Journal of Biochemistry \&amp; Cell Biology 2002, 34, 1544-1556.

8. Menke, N. B.; Ward, K. R.; Witten, T. M.; Bonchev, D. G.; Diegelmann, R. F. Clinics in Dermatology 2007, 25, 19-25.

9. James, T. J.; Hughes, M. A.; Cherry, G. W.; Taylor, R. P. Wound Repair and Regeneration 2003, 11, 172-176.

10. Wysocki, A. B.; Staiano-Coico, L.; Grinnell, F. J Investig Dermatol 1993, 101, 64-68.

11. Palolahti, M.; Lauharanta, J.; Stephens, R. W.; Kuusela, P.; Vaheri, A. Experimental Dermatology 1993, 2, 29-37.

12. Eming, S.; Smola, H.; Hartmann, B.; Malchau, G.; Wegner, R.; Krieg, T.; Smola-Hess, S. Biomaterials 2008, 29, 2932-2940.

13. Schonfelder, U.; Abel, M.; Wiegand, C.; Klemm, D.; Elsner, P.; Hipler, U. C. Biomaterials 2005, 26, 6664-6673.

14. Huo, Y.; Qiu, W.-Y.; Pan, Q.; Yao, Y.-F.; Xing, K.; Lou, M. F. Experimental Eye Research 2009, 89, 876-886.

15. Waddington, R. J.; Moseley, R.; Embery, G. Oral Diseases 2000, 6, 138-151.

16. Singh, B.; Pal, L. European Polymer Journal 2008, 44, 3222-3230.

17. Baier Leach, J.; Bivens, K. A.; Patrick Jr, C. W.; Schmidt, C. E. Biotechnology and Bioengineering 2003, 82, 578-589.

18. Luo, Y.; Kirker, K. R.; Prestwich, G. D. Journal of Controlled Release 2000, 69, 169-184.

19. Cerqueira Barros, S.; Martins, J. A.; Marcos, J. C.; Cavaco-Paulo, A. Enzyme Microbial Technology 2012, 107-114.

20. Vasconcelos, A.; Barros, S.; Cavaco-Paulo, A. Proceedings 6th International Conference on Textile and Polymer Biotechnology 2009, 273-274.

21. Vasconcelos, A.; Pêgo, A. P.; Henriques, L.; Lamghari, M.; Cavaco-Paulo, A. Biomacromolecules 2010, 11, 2213-2220.

22. Del Mar, E. G.; Largman, C.; Brodrick, J. W.; Fassett, M.; Geokas, M. C. Biochemistry 1980, 19, 468-472.

23. Cross, N. L. J Androl 1990, 11, 409-413.

24. Kristjansson, M. M., Activity Measurements of Proteinases Using Synthetic Substrates. In Current Protocols in Food Analytical Chemistry, John Wiley \& Sons, Inc.: 2001

25. Lestienne, P.; Bieth, J. G. Journal of Biological Chemistry 1980, 255, 9289-9294.

26. Huang, Y.; Surichamorn, W.; Cao, G.; Meng, M.; Pou, S.; Rosen, G.; Salcedo, T.; Strimpler, A.; Veale, C.; Bernstein, P.; Bonuccelli, C. Journal of Leukocyte Biology 1998, 64, 322-330.

27. Wasil, M.; Halliwell, B.; Hutchison, D. C.; Baum, H. Biochem. J. 1987, 243, 219-223.

28. Green, T. R.; Fellman, J. H.; Eicher, A. L. FEBS Letters 1985, 192, 33-36.

29. Wang, L.; Bassiri, M.; Najafi, R.; Najafi, K.; Yang, M.; B Khosrovi, B.; Hwong, W.; Barati, E.; Belisle, B.; Celeri, C.; Robson, M. J Burns Wounds 2007, 6, 65-79.

30. Albrich, J. M.; McCarthy, C. A.; Hurst, J. K. Proceedings of the National Academy of Sciences of the United States of America 1981, 78, 210-214.

31. Weiss, S. J.; Klein, R.; Slivka, A.; Wei, M. The Journal of Clinical Investigation 1982, 70, 598-607.

32. Hughes, M. N.; Nicklin, H. G. Journal of the Chemical Society A: Inorganic, Physical, Theoretical 1968, 450-452.

33. Matarrese, P.; Straface, E.; Pietraforte, D.; Gambardella, L.; Vona, R.; Maccaglia, A.; Minetti, M.; Malorni, W. The FASEB Journal 2005, 19, 416-418. 
34. Koppenol, W. H.; Moreno, J. J.; Pryor, W. A.; Ischiropoulos, H.; Beckman, J. S. Chemical Research in Toxicology 1992, 5, 834-842.

35. Martinez, G. R.; Di Mascio, P.; Bonini, M. G.; Augusto, O.; Briviba, K.; Sies, H.; Maurer, P.; Röthlisberger, U.; Herold, S.; Koppenol, W. H. Proceedings of the National Academy of Sciences 2000, 97, 10307-10312.

36. Reed, J. W.; Ho, H. H.; Jolly, W. L. Journal of the American Chemical Society 1974, 96, 1248-1249.

37. Pou, S.; Nguyen, S. Y.; Gladwell, T.; Rosen, G. M. Biochimica et Biophysica Acta (BBA) General Subjects 1995, 1244, 62-68.

38. Link, E. M.; Riley, P. A. Biochem. J. 1988, 249, 391-399.

39. McCord, J. M.; Fridovich, I. Journal of Biological Chemistry 1969, 244, 6049-6055.

40. Van Gelder, B. F.; Slater, E. C. Biochimica et Biophysica Acta 1962, 58, 593-595.

41. Hille, R.; Massey, V. J. Biol. Chem. 1981, 256, 9090-9095.

42. Bieth, J.; Spiess, B.; Wermuth, C. G. Biochemical Medicine 1974, 11, 350-357.

43. Laemmli, U. K. Nature 1970, 227, 680-685.

44. Burns, J. W. H., MA), Cox, Steven (Boston, MA), Walts, Alan E. (Reading, MA) Water insoluble derivatives of hyaluronic acid. 1991.

45. Collins, M.; Birkinshaw, C. Journal of Materials Science: Materials in Medicine 2008, 19, 3335-3343.

46. Edwards, J. V.; Howley, P.; Cohen, I. K. International Journal of Pharmaceutics 2004, 284, 1-12.

47. Edwards, J. V.; Phyllis, S. H. Journal of Biomedical Materials Research Part A 2007, 83A, 446-454.

48. Edwards, J. V.; Howley, P.; Davis, R.; Mashchak, A.; Goheen, S. C. International Journal of Pharmaceutics 2007, 340, 42-51.

49. Edwards, J. V.; Eggleston, G.; Yager, D. R.; Cohen, I. K.; Diegelmann, R. F.; Bopp, A. F. Carbohydrate Polymers 2002, 50, 305-314.

50. Grutter, M. G.; Fendrich, G.; Huber, R.; Bode, W. Embo Journal 1988, 7, 345-351.

51. Umezawa, K.; Matsushima, T.; Sugimura, T. Proc. Japan Acad. 1977, 53, 30-33.

52. Okura, A.; Morishima, H.; Takita, T.; Aoyagi, T.; Takeuchi, T.; Umezawa, H. The Journal of Antibiotics 1975, 28, 337-339.

53. James, H. L.; Wachtfogel, Y. T.; James, P. L.; Zimmerman, M.; Colman, R. W.; Cohen, A. B. The Journal of Clinical Investigation 1985, 76, 2330-2337.

54. Umezawa, H.; Aoyagi, T.; Okura, A.; Morishima, H.; Takeuchi, T.; Okami, Y. Journal of Antibiotics 1973, 26, 787-789.

55. Cornish-Bowden, A. Fundamentals of enzyme kinetics; Portland Press Ltd.: London, 2004; p 422.

56. Carp, H.; Janoff, A. The Journal of Clinical Investigation 1979, 63, 793-797.

57. Matheson, N. R.; Travis, J. Biochemistry 1985, 24, 1941-1945.

58. Ossanna, P. J.; Test, S. T.; Matheson, N. R.; Regiani, S.; Weiss, S. J. The Journal of Clinical Investigation 1986, 77, 1939-1951.

59. Dean, R. T.; Nick, H. P.; Schnebli, H. P. Biochemical and Biophysical Research Communications 1989, 159, 821-827.

60. Clark, R. A.; Stone, P. J.; El Hag, A.; Calore, J. D.; Franzblau, C. Journal of Biological Chemistry 1981, 256, 3348-3353.

61. Matheson, N. R.; Wong, P. S.; Schuyler, M.; Travis, J. Biochemistry 1981, 20, 331-336.

62. Matheson, N. R.; Wong, P. S.; Travis, J. Biochemical and Biophysical Research Communications 1979, 88, 402-409.

63. Boudier, C.; Bieth, J. G. Biochem J 1994, 303 ( Pt 1), 61-68.

64. Boudier, C.; Cadène, M.; Bieth, J. G. Biochemistry 1999, 38, 8451-8457.

65. Weiss, S. J. New England Journal of Medicine 1989, 320, 365-376. 
66. Reddy, V. Y.; Desorchers, P. E.; Pizzo, S. V.; Gonias, S. L.; Sahakian, J. A.; Levine, R. L.; Weiss, S. J. Journal of Biological Chemistry 1994, 269, 4683-4691.

67. Berndt, C.; Lillig, C. H.; Holmgren, A. American Journal of Physiology - Heart and Circulatory Physiology 2007, 292, H1227-H1236.

68. Yoshihara, E.; Chen, Z.; Matsuo, Y.; Masutani, H.; Yodoi, J., Chapter five - Thiol redox transitions by thioredoxin and thioredoxin-binding protein-2 in cell signaling. In Methods in Enzymology, Enrique, C.; Lester, P., Eds. Academic Press: 2010; Vol. Volume 474, pp 67-82.

69. Hancock, J.; Desikan, R.; Harrison, J.; Bright, J.; Hooley, R.; Neill, S. Journal of Experimental Botany 2006, 57, 1711-1718.

70. Green, J.; Paget, M. S. Nat Rev Micro 2004, 2, 954-966.

71. Chen, W. Y. J.; Abatangelo, G. Wound Repair and Regeneration 1999, 7, 79-89.

72. Wiegand, C.; Schönfelder, U.; Abel, M.; Ruth, P.; Kaatz, M.; Hipler, U.-C. Archives of Dermatological Research 2010, 302, 419-428.

\section{TABLES}

Table I Apparent kinetic parameters, Michaelis-Menten constant $\left(\mathrm{K}_{\mathrm{m}}\right)$, maximum enzyme velocity $\left(\mathrm{V}_{\max }\right)$ and inhibition dissociation constants $\left(\mathrm{K}_{\mathrm{ic}}\right.$ and $\left.\mathrm{K}_{\mathrm{iu}}\right)$ for Human Neutrophil Elastase (HNE) and Porcine Pancreatic Elastase (PPE) in presence of different concentrations of inhibitor-peptide Pep4. 
Table II Apparent kinetic parameters, Michaelis-Menten constant $\left(\mathrm{K}_{\mathrm{m}}\right)$, maximum enzyme velocity $\left(\mathrm{V}_{\max }\right)$ and inhibition dissociation constants $\left(\mathrm{K}_{\mathrm{ic}}\right.$ and $\left.\mathrm{K}_{\mathrm{iu}}\right)$ for Human Neutrophil Elastase (HNE) and Porcine Pancreatic Elastase (PPE) in presence of different concentrations of inhibitor-peptide Pep4M.

Table III Inhibition dissociation constant $\left(\mathrm{K}_{\mathrm{ic}}\right)$ for Porcine Pancreatic Elastase (PPE) and Human Neutrophil Elastase (HNE) in presence of elastatinal.

\section{FIGURES}


FIGURE 1 Image of a hyaluronic acid (HA) hydrogel film. HA hydrogel films were prepared by autocrosslinking as previously reported by Burns and co-workers ${ }^{44}$.

FIGURE 2 Schematic representation of the N-terminal domain of SLPI and its disulfide connectivities. Disulfide bonds are displayed by solid lines while inter-main-chain hydrogen bonds are represented by dashed lines. The Pep4 sequence is highlighted with grey circles. The current image was adapted from Grütter and Bode X-ray study on SLPI structure ${ }^{50}$.

FIGURE 3 Reaction velocity plots for porcine pancreatic elastase $(0.3$ units $/ \mathrm{mL})$ and human neutrophil elastase $(0.5$ units $/ \mathrm{mL})$ in presence of Pep4. Kinetic parameters were determined by nonlinear regression analysis, Michaelis-Menten plot a) and c) and by linear regression studies, Direct Linear plot b) and d), for PPE and HNE respectively. In the Direct Linear plots the black lines correspond to the elastase enzymatic assay without inhibitor and the grey lines to the enzymatic assay performed in presence of Pep4 (1 $\mu \mathrm{M}$ and $32 \mu \mathrm{M}$ of Pep4 in the PPE and HNE assay, respectively). The current assays were performed in triplicate.

FIGURE 4 Influence of DTT on the kinetic parameters, $K_{m}$, ( $\square$ ) and $V_{\max }$, ( $\square$ ) of Porcine Pancreatic Elastase (PPE) in the presence of $8 \mu \mathrm{M}$ of Pep4. Each data point represents the average of three independent determinations.

FIGURE 5 Reaction velocity plots for porcine pancreatic elastase $(0.3$ units $/ \mathrm{mL})$ and human neutrophil elastase $(0.5$ units $/ \mathrm{mL})$ in presence of Pep4M. Kinetic parameters were determined by nonlinear regression analysis, Michaelis-Menten plot a) and c) and by linear regression studies, Direct Linear plot b) and d), for PPE and HNE respectively. In the Direct Linear plots the black lines correspond to the elastase enzymatic assay without inhibitor and the grey lines to the enzymatic assay performed in presence of Pep4M $(4 \mu \mathrm{M}$ and $1 \mu \mathrm{M}$ of Pep4M in the PPE and HNE assay, respectively). The current assays were performed in triplicate.

FIGURE 6 Schematic representation of the models for competitive inhibition a) and mixed inhibition b). Adapted from the reference ${ }^{55}$. 
FIGURE 7 Influence of inhibitor concentrations (Pep4 and Pep4M) on Vmax/Km ratio for the PPE a) and HNE b) reactions. The PPE and HNE assays were represented by triangles and squares, respectively, while the presence of Pep4 and Pep4M were represented by dark and light grey lines.

FIGURE 8 Effect of hydrogen peroxide $\left(\mathrm{H}_{2} \mathrm{O}_{2}\right)$, hypochlorous acid $(\mathrm{HOCl})$, peroxinitrite $\left(\mathrm{ONOO}^{-}\right)$and superoxide anion $\left(\mathrm{O}_{2}{ }^{-}\right)$on elastase inhibitory activity of Pep4 a), Pep4M b) and elastatinal c). PPE activity was determined spectrophotometrically at $410 \mathrm{~nm}$, using as substrate $\mathrm{N}$-succinyl-Ala-Ala-Ala- -nitroanilide. These assays were performed in presence of inhibitor $(\Xi)$ with oxidante $(\square)$ with oxidante + albumin $(\square)$ treatment and without inhibitor $(\square)$. Experiments were performed under identical conditions with or without oxidant treatment. Data shown are the average of three independent measurements.

FIGURE 9 Effect of hydrogen peroxide $\left(\mathrm{H}_{2} \mathrm{O}_{2}\right)$ on elastase inhibitory activity of Pep4M. PPE activity was assayed spectrophotometrically at $410 \mathrm{~nm}$ using N-succinyl-Ala-Ala-Ala- $p$ nitroanilide as substrate, in presence of Pep4M in different oxidative mixtures: Pep4M+ $\mathrm{H}_{2} \mathrm{O}_{2}$; Pep4M+ $\mathrm{H}_{2} \mathrm{O}_{2}+\mathrm{BSA}$; Pep4M+BSA; $\mathrm{H}_{2} \mathrm{O}_{2}+\mathrm{BSA} ; \mathrm{H}_{2} \mathrm{O}_{2}$ and BSA. Data shown are the mean \pm $\mathrm{SD}$ of triplicate determinations.

FIGURE 10 Visualization of potential reaction products from the reaction albumin + hydrogen peroxide by SDS-PAGE. Electrophorese gels were prepared using 4\% stacking gels and $8 \%$ resolving gels. Gel revelation was performed with Coomassie blue.

Lane 1: Protein markers; lane 2: BSA $(0.125 \mathrm{mg} / \mathrm{mL})+\mathrm{H}_{2} \mathrm{O}_{2}(0.25 \mathrm{mM})$, incubation time $=22$ hours; lane 3: BSA $(0.125 \mathrm{mg} / \mathrm{mL})+\mathrm{H}_{2} \mathrm{O}_{2}(0.25 \mathrm{mM})$, incubation time $=2$ hours; lane 4: BSA $(0.125 \mathrm{mg} / \mathrm{mL})$; lane 5 : BSA $(0.25 \mathrm{mg} / \mathrm{mL})+\mathrm{H}_{2} \mathrm{O}_{2}(0.50 \mathrm{mM})$, incubation time $=22$ hours; lane 6: BSA $(0.25 \mathrm{mg} / \mathrm{mL})+\mathrm{H}_{2} \mathrm{O}_{2}(0.50 \mathrm{mM})$, incubation time $=2$ hours; lane $7: \mathrm{BSA}(0.25 \mathrm{mg} / \mathrm{mL})$; lane 8: protein marker; lane 9: $\mathrm{BSA}(0.50 \mathrm{mg} / \mathrm{mL})+\mathrm{H}_{2} \mathrm{O}_{2}(1.0 \mathrm{mM})$, incubation time $=22$ hours; lane 10: BSA $(0.50 \mathrm{mg} / \mathrm{mL})+\mathrm{H}_{2} \mathrm{O}_{2}(1.0 \mathrm{mM})$, incubation time $=2$ hours; lane 11: BSA $(0.50$ $\mathrm{mg} / \mathrm{mL})$; lane 12: BSA $(1.0 \mathrm{mg} / \mathrm{mL})+\mathrm{H}_{2} \mathrm{O}_{2}(2.0 \mathrm{mM})$, incubation time $=22$ hours; lane 13: BSA $(1.0 \mathrm{mg} / \mathrm{mL})+\mathrm{H}_{2} \mathrm{O}_{2}(2.0 \mathrm{mM})$, incubation time $=2$ hours; lane 14: BSA $(1.0 \mathrm{mg} / \mathrm{mL})$; lane 15 : BSA $(2.0 \mathrm{mg} / \mathrm{mL})+\mathrm{H}_{2} \mathrm{O}_{2}(4.0 \mathrm{mM})$, incubation time $=22$ hours; lane 16 : BSA $(2.0$ $\mathrm{mg} / \mathrm{mL})+\mathrm{H}_{2} \mathrm{O}_{2}(4.0 \mathrm{mM})$, incubation time $=2$ hours; lane 17: BSA $(2.0 \mathrm{mg} / \mathrm{mL})$. 
FIGURE 11 Visualization of potential reaction products from the reaction albumin + hydrogen peroxide by SDS-PAGE. Electrophorese gels were prepared using $4 \%$ stacking gels and $10 \%$ resolving gels. Gel revelation was performed with Coomassie blue.

Lane 1: Protein markers; lane 2: BSA $(0.125 \mathrm{mg} / \mathrm{mL})+\mathrm{H}_{2} \mathrm{O}_{2}(0.25 \mathrm{mg} / \mathrm{mL})$, incubation time $=$ 22 hours; lane 3: BSA $(0.125 \mathrm{mg} / \mathrm{mL})+\mathrm{H}_{2} \mathrm{O}_{2}(0.25 \mathrm{mM})$, incubation time $=2$ hours; lane 4 : BSA $(0.125 \mathrm{mg} / \mathrm{mL})$; lane 5: BSA $(0.25 \mathrm{mM})+\mathrm{H}_{2} \mathrm{O}_{2}(0.50 \mathrm{mg})$, incubation time $=22$ hours; lane 6: BSA $(0.25 \mathrm{mg} / \mathrm{mL})+\mathrm{H}_{2} \mathrm{O}_{2}(0.50 \mathrm{mM})$, incubation time $=2$ hours; lane $7: \mathrm{BSA}(0.25 \mathrm{mg} / \mathrm{mL})$.

FIGURE 12 Evaluation of the effect of HA hydrogel formulations on elastase activity. The measurement of elastase activity at physiological conditions (36 mU/mL PPE and HNE) was performed spectrophotometrically by monitoring the release of $p$-nitroaniline at $410 \mathrm{~nm}$ from the enzymatic hydrolysis of the substrate $\mathrm{N}$-succinyl-Ala-Ala-Ala-p-nitroanilide $(4.4 \mathrm{mM})$ and MeOSuccinyl-Ala-Ala-Pro-Val-p-nitroanilide $(3.0 \mathrm{mM})$, respectively. The HA hydrogel formations tested in the PPE ( $\square)$ and HNE ( $\square$ ) assays, contain Pep4 (1 and $32 \mu \mathrm{M})$, Pep4M (4 and $1 \mu \mathrm{M})$ and elastatinal $(64 \mu \mathrm{M})$, respectively. Data shown represent the mean of three assays $\pm \mathrm{SD}$. 